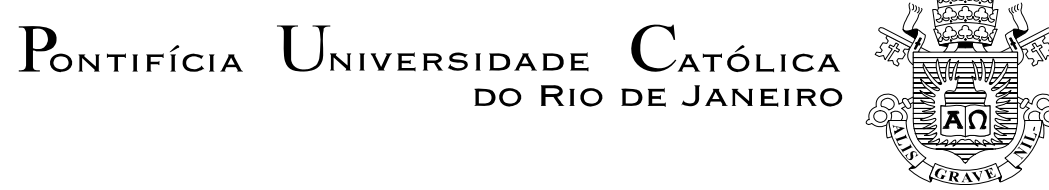

Milena de Uzeda Garrão

\title{
O CÓRPUS NÃO MENTE JAMAIS: SOBRE A IDENTIFICAÇÃO E USO DE COMBINAÇÕES MULTIVOCABULARES DO TIPO VERBO MAIS SINTAGMA NOMINAL
}

Tese de Doutorado

Tese apresentada ao Departamento de Letras da Pontifícia Universidade Católica do Rio de Janeiro como requisito parcial para obtenção do título de Doutor em Letras (Estudos da Linguagem).

Orientador: Profa Doutora Maria Carmelita Pádua Dias 


$$
\text { Pontifícia Universidade } \text { Católica }_{\text {Do Rio de Janeiro }}
$$

\section{O CÓRPUS NÃO MENTE JAMAIS: SOBRE A IDENTIFICAÇÃO E USO DE COMBINAÇÕES MULTIVOCABULARES DO TIPO VERBO MAIS SINTAGMA NOMINAL}

Tese apresentada ao Departamento de Letras da Pontifícia Universidade Católica do Rio de Janeiro como requisito parcial para obtenção do título de Doutor em Letras (Estudos da Linguagem). Aprovada pela Comissão Examinadora abaixo assinada.

Prof $^{\mathrm{a}}$ Doutora Maria Carmelita Pádua Dias Orientadora Departamento de Letras - PUC-Rio

Prof $^{\mathrm{a}}$ Helena Franco Martins Departamento de Letras - PUC-Rio Prof $^{a}$ Violeta de San Tiago Dantas Barbosa Quental Departamento de Letras - PUC-Rio

Prof $^{a}$ Solange Coelho Vereza Departamento de Letras Estrangeiras Modernas - UFF

Prof $^{a}$ Rove Luiza de Oliveira Chishman UNISINOS

Prof. Paulo Fernando Carneiro de Andrade Coordenador Setorial do Centro de Teologia e Ciências Humanas - PUC-Rio

Rio de Janeiro, 24 de Março de 2006 
Todos os direitos reservados. É proibida a reprodução total ou parcial do trabalho sem autorização do autor, do orientador e da universidade.

\section{Milena de Uzeda Garrão}

Graduou-se em Letras (Tradução-português/inglês) pela PUC-Rio, em 1997. Obteve seu título de Mestre em Estudos da Linguagem pela mesma instituição em 2001, na área de Tradução Automática. Neste mesmo ano atuou como professora de Lingüística no Departamento de Estudos da Linguagem da UERJ. Em 2002, colaborou com a implementação do CLIC (Centro de Lingüística Computacional da PUC-Rio). Tem como principais interesses, a Lexicografia, a Tradução Automática e a Lingüística de Córpus.

Ficha Catalográfica

Garrão, Milena de Uzeda

O córpus não mente jamais : sobre a identificação e uso de combinações multivocabulares do tipo verbo mais sintagma nominal / Milena de Uzeda Garrão; orientadora: Maria Carmelita Pádua Dias. - Rio de Janeiro : PUC, Departamento de Letras, 2006.

124 f. ; $30 \mathrm{~cm}$

Tese (doutorado) - Pontifícia Universidade Católica do Rio de Janeiro, Departamento de Letras.

Inclui referências bibliográficas.

1. Letras - Teses. 2. Combinações Multivocabulares. 3. Colocações Verbais. 4. Lexicografia de Córpus. 5. Semântica de Córpus. I. Dias, Maria Carmelita Pádua. II. Pontifícia Universidade Católica do Rio de Janeiro. Departamento de Letras. III. Título. 


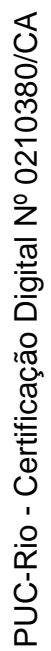

A meus pais, Nani e Mel. 


\section{Agradecimentos}

Aos meus pais e ao Ernani, pela ajuda preciosa com a nossa adorada Mel.

À professora Helena Martins, não somente pelos escritos e aulas inspiradores mas, principalmente, por ter me escoltado neste caminho teórico ainda não amplamente explorado dentro da Lingüística.

Aos amigos do Clic, sobretudo:

à professora Claudia Oliveira, do Instituto Militar de Engenharia, pela amizade e idealismo, e pela adaptação e realização computacional do Modelo de Espaço Vetorial aos fins propostos.

à professora Maria Claudia Freitas, pelas idéias compartilhadas e pela ajuda com a aplicação do Modelo.

ao Cícero Nogueira, Doutorando do Departamento de Informática da PUC-Rio, pela implementação do extrator $\mathrm{V}+\mathrm{SN}$ e por ter me socorrido com a realização dos testes estatísticos.

Ao corpo docente da pós-graduação do Departamento de Letras da PUCRio, principalmente às professoras Margarida Basílio e Violeta Quental, pela clareza nos ensinamentos.

À Chiquinha, da secretaria de pós-graduação do Departamento de Letras da PUC-Rio, pela ajuda sempre pontual durante os quatro anos de curso.

À Capes, pela bolsa de estudos que me foi concedida.

À Banca Examinadora, pela sua excelência e pelos comentários e sugestões preciosos.

E especialmente, à professora Maria Carmelita Pádua Dias, pelo incentivo, pela amizade, mas sobretudo, por ter aberto mão de algumas de suas convicções teóricas para, mais uma vez, presentear-me com sua orientação sempre precisa e terna. 


\section{Resumo}

Garrão, Milena de Uzeda; Dias, Maria Carmelita Pádua. O córpus não mente jamais: sobre a identificação e uso de combinações multivocabulares do tipo verbo mais sintagma nominal. Rio de Janeiro, 2006. 124 p. Tese de Doutorado - Departamento de Letras, Pontifícia Universidade Católica do Rio de Janeiro.

Muitos estudos recentes sobre a identificação e uso de combinações multivocabulares (CMs) adotam uma perspectiva representacionista do significado da palavra. Este estudo propõe que é muito mais interessante identificar as CMs por um olhar não-representacionista. A metodologia proposta foi testada em CMs do tipo $\mathrm{V}+\mathrm{SN}$, um padrão bastante freqüente no português do Brasil (PB). Trata-se de uma análise estatística com base em córpus que pode ser resumida em três etapas: 1) córpus robusto do PB como base de análise, 2) aplicação de um teste estatístico ao córpus, a saber, teste de Logaritmo de Verossimilhança (Banerjee \& Pedersen, 2003), para detecção das CMs mais freqüentes com padrão V+SN (como tomar café) e exclusão de co-ocorrências sintáticas aleatórias dos mesmos itens lexicais, 3)aplicação de Medidas de Similaridade (Baeza-Yates \& Ribeiro-Neto, 1999) entre todos os parágrafos contendo uma certa CM (por exemplo, fazer campanha) e todos os parágrafos contendo o substantivo fora da CM (campanha). Esta última etapa foi utilizada para avaliar o grau de composicionalidade da CM. Pôde-se concluir que quanto maior a similaridade entre os parágrafos contendo a CM e os parágrafos contendo o substantivo fora da expressão, maior será o grau de composicionalidade da CM. Por essa razão, este estudo tem um impacto tanto teórico quanto prático para a semântica.

\section{Palavras-chave}

Combinações Multivocabulares; Colocações Verbais; Lexicografia de Córpus; Semântica de Córpus 


\section{Abstract}

Garrão, Milena de Uzeda; Dias, Maria Carmelita Pádua (Advisor). The corpus never lies: on the identification and use of multiword expressions of the pattern verb plus noun phrase. Rio de Janeiro, 2006.124 p. PhD Thesis - Departamento de Letras, Pontifícia Universidade Católica do Rio de Janeiro.

A considerable amount of recent researches on defining multi-word expressions' (MWE) phenomenon has an underlying representational framework of word meaning. In this study we claim that it is much more interesting to view MWE from a non-representational perspective. By choosing this path, we avoid the time-consuming and controversial human intuitions to MWE identification and definition. Our methodology was tested on Brazilian Portuguese verbal phrases of $\mathrm{V}+\mathrm{NP}$ pattern. It is a statistically-based corpus analysis which could be summed up as the following three sequent steps: 1) robust linguistic corpora as output, 2) application of a probabilistic test to the corpora, namely Log Likelihood test (Banerjee \& Pedersen, 2003), in order to spot the Portuguese MWEs of V+NP pattern (such as tomar cafe) and disregard casual syntactic and not otherwise motivated co-occurrences of the same lexical items, 3) application of Similarity Measures (Baeza-Yates \& Ribeiro-Neto, 1999) between all the paragraphs containing a certain MWE and all the paragraphs containing its separate noun. This latter step is crucial to assess the MWE compositionality level. We conclude that the higher are the similarity measures between the MWE (such as fazer campanha) and its separate noun (campanha), the more compositional will be the MWE. Therefore, we believe that this work has both a practical and a theoretical impact to semantics.

\section{Keywords}

Multiword Expressions; Verbal Collocations; Corpus Lexicography, Corpus Semantics. 


\section{Sumário}

1.Pulga atrás da orelha 12

1.1.Caracterização do problema 12

1.2. Desconfianças teóricas e caminhos alternativos 13

1.3. Objetivos 15

$\begin{array}{ll}\text { 1.4. Organização } & 18\end{array}$

2. Combinação Multivocabular: da palavra como representação a seus desdobramentos teóricos

2.1. Sobre o significado e a representação de entidades extralingüísticas

2.1.1. Representacionismo na Lingüística 23

2.2. Neo-representacionismo e sua ascendência filosófica 26

2.2.1. Neo-representacionismo na Lingüística 29

2.3. As CMs sob os dois ângulos de representação 35

2.3.1. Multivocábulos e o representacionismo: a profusão de rótulos da semântica da inocência 36

2.3.2. Multivocábulos e o neo-representacionismo: sinais de difusão teórica 42

2.4. Discussão preliminar $\quad 45$

3. Por um caminho não-representacionista para a detecção dos multivocábulos $\quad 48$

3.1 A herança filosófica 48

3.2. Ecos do não-representacionismo na Lingüística e em PLN 51

3.3. A inevitabilidade do paradoxo do córpus 53

3.3.1. O córpus utilizado: CETENFolha 55

3.4. O teor estatístico do fenômeno lingüístico 56

3.4.1. Mãos à obra $\quad 57$

3.5. A identificação das CMs 64 
3.5.1. Testagem de hipóteses

3.5.1.1. O teste e a avaliação dos resultados

4. Composicionalidade com base em córpus

4.1. Passo-a-passo do método

4.2. Aferição do grau de composicionalidade das CMs

4.3. Avaliação dos resultados

5. Discussão, aplicação e trabalhos futuros

6. Referências Bibliográficas 


\section{Lista de Tabelas e Quadros}

Tabela 1- freqüência absoluta dos 30 verbos mais recorrentes no córpus

Tabela 2 - freqüência de verbos mais recorrentes do córpus

CETENFolha seguidos facultativamente de

deteminante e obrigatoriamente de um nome

62

Tabela 3 - freqüência de verbos seguidos facultativamente de deteminante e obrigatoriamente de um nome posposto por marcas de pontuação ou advérbio 63

Tabela 4 - resultados com verbo fazer 107

Tabela 5 - resultados com o verbo ter 107

Tabela 6 - resultados com o verbo dar 108

Tabela 7 - resultados com o verbo perder 108

Tabela 8 - resultados com o verbo usar 109

Tabela 9 - resultados com o verbo receber 109

Tabela 10 - resultados com o verbo deixar 109

Tabela 11 - resultados com o verbo tomar 110

Tabela 12 - resultados com o verbo ganhar 110

Tabela 13 - resultados com o verbo criar

Tabela 14 - resumo qualitativo dos resultados

Quadro 1 - alguns microcontextos de partido / tomar partido

Quadro 2 - alguns microcontextos de bandeira / dar bandeira

Quadro 3 - alguns microcontextos de banho/ tomar banho

Quadro 4 - microcontextos de camisinha / usar camisinha

Quadro 5 - microcontextos de cafél tomar café 
A coisa parece fácil: o fora em torno do dentro, o alto em cima do baixo.

Mas essa ordem serena é coisa dura e avessa, uma máquina perversa.

Para instaurar esse mundo precisa a vontade mais crassa, a desfaçatez de quem sempre procura aquilo que acha.

Precisa de olhos sem trégua e mãos cegas, abissais, com dedos destros, capazes de gestos antinaturais.

Paulo Henriques Britto (Trovar Claro) 